OPEN ACCESS

Edited by:

Sujith V. Sajja,

Walter Reed Army Institute of Research, United States

Reviewed by: Ramesh Rajan,

Monash University, Australia Francisco Capani, University of Buenos Aires, Argentina

*Correspondence: Lauren E. Sergio Isergio@yorku.ca

Specialty section: This article was submitted to Neurotrauma, a section of the journal

Frontiers in Neurology

Received: 02 April 2020 Accepted: 12 August 2020 Published: 16 September 2020

Citation:

Sergio LE, Gorbet DJ, Adams MS and Dobney DM (2020) The Effects of Mild

Traumatic Brain Injury on Cognitive-Motor Integration for Skilled Performance.

Front. Neurol. 11:541630 doi: 10.3389/fneur.2020.541630

\section{The Effects of Mild Traumatic Brain Injury on Cognitive-Motor Integration for Skilled Performance}

\author{
Lauren E. Sergio ${ }^{1,2 *}$, Diana J. Gorbet ${ }^{1,2}$, Meaghan S. Adams ${ }^{1,3,4}$ and Danielle M. Dobney ${ }^{1,3}$ \\ ${ }^{1}$ School of Kinesiology and Health Science, York University, Toronto, ON, Canada, ${ }^{2}$ Centre for Vision Research, York \\ University, Toronto, ON, Canada, ${ }^{3}$ Vision-Science to Application (VISTA) Program, York University, Toronto, ON, Canada, \\ ${ }^{4}$ Toronto Rehabilitation Institute, University Health Network, Toronto, ON, Canada
}

Adults exposed to blast and blunt impact often experience mild traumatic brain injury, affecting neural functions related to sensory, cognitive, and motor function. In this perspective article, we will review the effects of impact and blast exposure on functional performance that requires the integration of these sensory, cognitive, and motor control systems. We describe cognitive-motor integration and how it relates to successfully navigating skilled activities crucial for work, duty, sport, and even daily life. We review our research on the behavioral effects of traumatic impact and blast exposure on cognitive-motor integration in both younger and older adults, and the neural networks that are involved in these types of skills. Overall, we have observed impairments in rule-based skilled performance as a function of both physical impact and blast exposure. The extent of these impairments depended on the age at injury and the sex of the individual. It appears, however, that cognitive-motor integration deficits can be mitigated by the level of skill expertise of the affected individual, suggesting that such experience imparts resiliency in the brain networks that underly the control of complex visuomotor performance. Finally, we discuss the next steps needed to comprehensively understand the impact of trauma and blast exposure on functional movement control.

Keywords: movement, cognition, eye-hand coordination, sensorimotor integration, concussion, blast exposure, neuroimaging, motor psychophysics

\section{A COMPLEX SKILL REQUIRES A COMPLEX BRAIN: AN INTRODUCTION TO THE NEURAL CONTROL OF RULE-BASED SKILLED PERFORMANCE \\ Imagine}

At work, you operate a drone aircraft. You have one joystick that sends the drone up or down and turns it in a circle, and another that flies it forward, back, or side to side, and all the while you look at a computer monitor showing images from the drone's camera to allow you to direct its movement. On break you enjoy a cup of tea, reaching your arm forward to pick up your teacup.

Operating the drone and reaching for the cup are examples of visually-guided arm movement that vary widely in their complexity. How are you able to perform these tasks proficiently and relatively effortlessly? Reaching for and interacting with objects in the environment is a common daily task, but one that can vary widely depending on task conditions. Looking at and then reaching for a teacup is an example of a direct interaction. The visual stimulus guiding the action is itself 
the target of the action. In contrast, remotely operating a drone is an example of an indirect interaction: there is an intermediary between the action and the target. Direct interactions are guided by standard sensorimotor mappings within the brain. Indirect interactions are guided by non-standard sensorimotor mapping, and rely on different neural computations that must incorporate the spatial dissociation of gaze, attention, and overt motor output (1).

"Transformational" non-standard mappings use specific spatial algorithms to relate the position of the visual cue to the direction of action, such as relating horizontal mouse movement to vertical cursor movement. The different levels of visuomotor compatibility in transformational mappings are achieved by two sensorimotor strategies: sensorimotor recalibration and visuomotor adaptation. Sensorimotor recalibration allows for adaptation to spatial orientation differences by remapping between two sensory modalities (2-4). Because this is an implicit recalibration, there are after-effects if the source of recalibration is removed. Think of the lightness you feel for the first few steps after taking a long trek with a heavy backpack. In comparison, visuomotor adaptation, or "strategic control" (5) relies on a mental rotation to align the required limb movement to the spatial location of a target. It is more explicit, does not produce after-effects, and can require rule integration. Note that these terms are not used consistently across the motor adaptation literature [for comprehensive reviews see $(6,7)$ ]. Lastly, in order to execute skilled movements smoothly and accurately, the brain must often account for various rule-based situations. Combining thought and action is a process known as cognitive-motor integration (CMI). CMI is essential for the completion of skilled activities that involve non-standard mappings and other complex skills, making it crucial for work, duty, sport, and daily life. While healthy adults perform CMI with little conscious awareness, these skills are not innate and can be affected by brain injury. In this paper, we review three related lines of research: sportrelated head impact and motor behavior, blast-related impact and motor behavior, and functional brain neurophysiology and motor behavior. The linking theme is the neural control of rulebased sensory-guided movement in health and following mild brain injury.

\section{A FAILURE TO COMMUNICATE: THE EFFECT OF MILD BRAIN INJURY ON COGNITIVE-MOTOR INTEGRATION BEHAVIOR}

While some acquired brain injury can impose distinct focal damage to specific brain regions, it is a more diffuse injury that typically arises from blast and concussive impact $(8,9)$. The acceleration and deceleration forces of concussive trauma initiate a "neurometabolic" cascade. This cascade invokes a state of energy crisis from both an increased glucose requirementneeded to restore ion homeostasis - and a decreased supply of glucose through reduced cerebral blood flow (10,11). Further, axonal injury occurs due to the mechanical shearing and tensile strain from acceleration, deceleration, and rotational forces (12). Such forces lead to altered axonal membrane permeability and ionic disruption, as well as cytoskeletal breakdown (10,11), all of which can impair neurotransmission. The time frame, however, for the recovery from these effects and their exact relationship to concussion symptoms is not fully understood.

We propose that widespread injury can reduce rule-based skilled performance through a failure to communicate between brain networks. Cognitive brain network alterations have been observed following concussion (13-17). To assess the communication between brain areas for movement control, our group developed a touch screen based functional assessment tool using a visuomotor task that incorporates two forms of non-standard mapping: explicit rule integration (strategic control), and implicit spatial vision-to-hand-motion realignment (sensorimotor recalibration). Portable software applications to assess brain function following injury are increasingly being developed, and offer a useful, pragmatic approach to providing information to the user and their caregivers (18-22). In our task, a basic standard mapping condition has the participant place their finger over a central start target on a vertical touch screen, immediately slide their finger on that same screen directly toward a target that appears, and hold it there. There is universal agreement among the hundreds of youth who have done this task that "it is the most boring video game ever." It does get more interesting for them, however. In the remaining three cognitive-motor integration (CMI) conditions, one or both forms of non-standard mapping are introduced. In the first CMI condition, the target and cursor are viewed on the vertical touch screen, but the motion of the cursor is reversed from the motion of the finger on that screen. We often see participants talking themselves through this condition ("target is down... slide up slide up!"), suggesting that we are indeed tapping into explicit rule integration associated with this mental rotation. In the second CMI condition, the touch screen recording finger movement is now laid flat in front of them, and the targets are still presented in the same vertical location as before (on a tablet or monitor). This condition requires a more implicit sensorimotor recalibration since the guiding visual information and required motor goal are in different spatial locations. Those who have grown up with computers and video games barely register this condition as a challenge. To this blasé tech-savvy group, however, we throw our third CMI condition, a combination of the two other CMI conditions: one must now think their way through moving opposite to an extrafoveal target (Figure 1A). There is, without fail, a reaction of surprise to this condition. Try it yourself now if you are at a computer with a mouse! Physically turn your mouse around, grab it with the bottom end pointing out, and move your cursor to an icon on your screen. Congratulations, you have just performed cognitive-motor integration using two forms of nonstandard mapping. Continue reading to find out what your brain just accomplished.

\section{How Does Concussion History Influence CMI Performance? Are They Really "Recovered"?}

There is evidence that individuals with concussion-a form of mild traumatic brain injury (mTBI) - have reduced capacity 

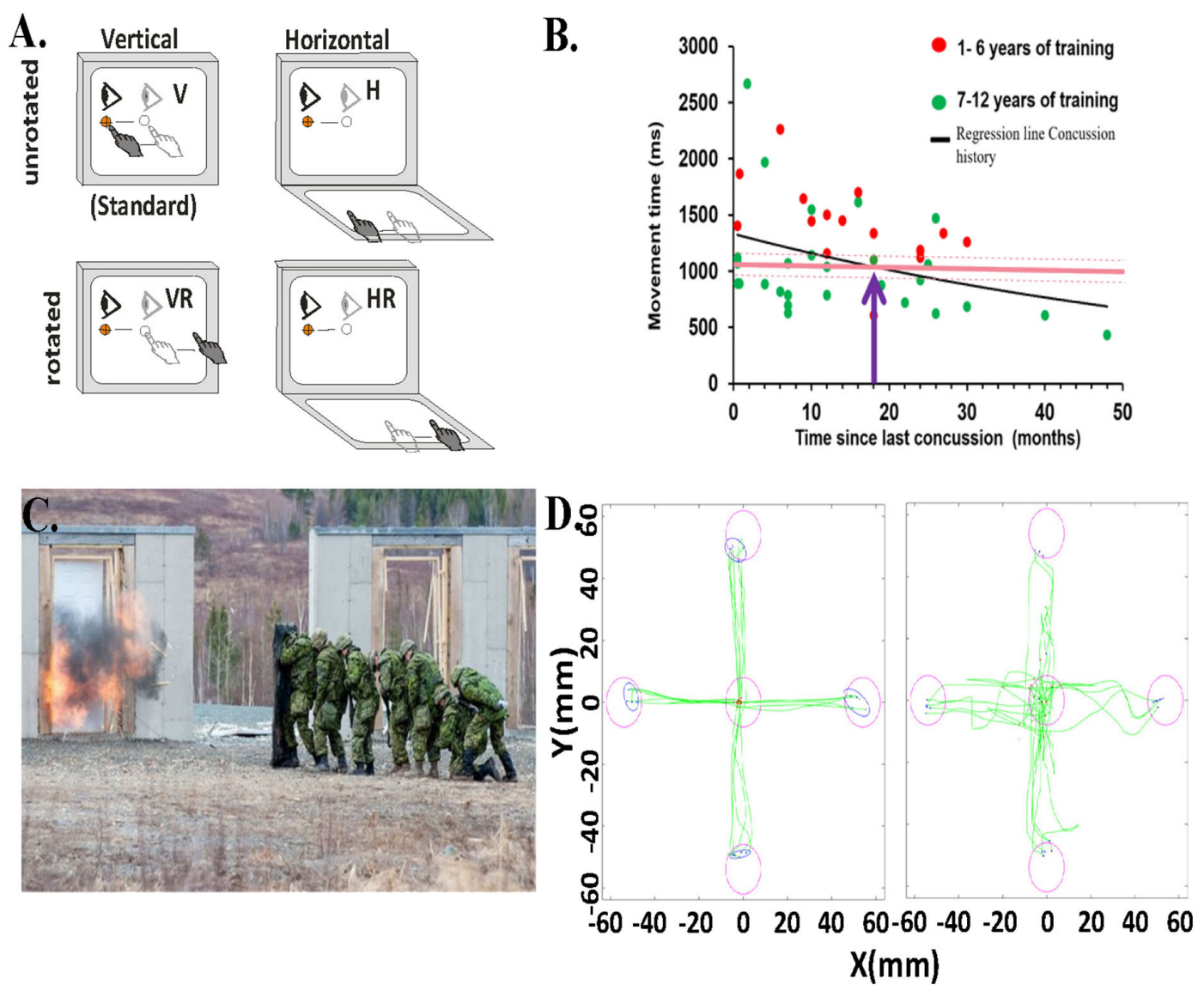

FIGURE 1 | Behavioral task and data. (A) Schematic of experimental conditions. Visual stimuli were presented on a vertical touchscreen. Motion was recorded on either that touch screen or a second one placed horizontally in front of the participant. Light gray eye and hand symbols indicate the start position. The dark gray eye and hand symbols depict the movement from start position toward the target. The target was presented in one of four locations (right, left, up, or down). $\mathrm{H}$, horizontally placed touchscreen; $\mathrm{V}$, vertically placed touch screen; $\mathrm{R}$, rotated $\left(180^{\circ}\right)$ visual feedback. (B) Relationship between the total movement time in the CMl condition and time since last concussion for each child with concussion history and asymptomatic (dots), represented by the regression line (black line). Red dots are those children with 1-6 years of training, green dots are those with 7 or more years of sport experience. Also included is the mean total movement time of the CMl condition of the healthy children (8-16 years old) with no concussion-history (dark pink horizontal line). The light pink dotted lines indicate the upper and lower confidence intervals of the control group's total movement time. The purple arrow denotes where the two lines of the concussion history and no-history controls cross. (C) Canadian Forces School of Military Engineering personnel participating in breaching exercises. Photo courtesy of Haley Voutour, 5th Canadian Division Support Group. (D) Examples of hand movement trajectories (green) in the Standard (direct interaction) and in the Plane Change+Feedback Reversal condition ("horizontal rotated") from one control participant (left panel) and from one breacher participant (right panel).

for executive function, slower cognitive processing speeds, and attention deficits (23). These data suggest that task switching, required when performing two tasks within the same domain ("dual-tasking"), will be more difficult for those with concussion. Concurrent task paradigms using both task switching and integration tasks (combining behaviors from two different domains) have been proposed as a means to assess concussion recovery. For example, there are subtle changes in oculomotor function, gait, and balance after concussion, which become more pronounced during both dual-task and integration paradigms $(23,24)$. Determining if an individual has recovered from concussion is a challenge from a risk management perspective. Clinicians understand the risk of returning athletes too soon to sport and yet the tools used to determine recovery are inadequate, testing one domain at a time (e.g., motor, cognition) or relying on self-report $(25,26)$. Thus, many individuals are returned to work and sport with impairments that may leave them vulnerable to further injury $(27,28)$.

We have used our task in several sport concussion studies (2932), and always observe significant differences in performance outcomes related to both timing and accuracy in concussed athletes vs. controls. We compared youth athletes (8-16 years old) with a history of concussion who were asymptomatic and deemed recovered (33) to age-matched controls with no history of concussion (30). There were no differences between groups on the simple, standard task. In contrast, in the nonstandard task, youth who reported a previous concussion were significantly slower in moving from the start to their first 
stopping point ("movement time," or MT), which was often before they got to the target. They were also slower in moving from the start to the end targets, a movement which comprised the initial ballistic MT plus the post-pause corrective movement to get to the final target (30). This finding indicates that concussion history is associated with slower non-standard skilled performance in these children, compared to their non-concussed peers. This finding was replicated in a similar cohort of youth athletes who also showed decreased accuracy and increased path variability (31). The significant differences we found in the group with a previous concussion did not subside and return to the level of the matched control group until on average 18 months post-concussion (Figure 1B); that's nearly two seasons later! This finding is concerning given that most youth will have returned to activity within this time frame and thus are likely more vulnerable to re-injury, concussive, or otherwise.

When we examined concussion history effects on CMI performance at the elite level, we found more subtle differences (32). In a study of 102 National Hockey League (NHL) draft prospects (mean age $=17$ years, all asymptomatic) we observed that previously concussed participants had significantly decreased reaction times (RT) on the non-standard task compared to the control group, indicating that they were slower to respond to the peripheral stimulus when it appeared (32). Given the dramatic increase in speed of the game between recreational-level and NHL-caliber athletes, we suggest that even minor changes in RT to a given stimulus may represent both a hazard to player safety and an influence on player performance. Noteworthy though are the attenuated effects of concussion on CMI in these elite vs. the non-elite young athletes in our other studies. Experience in complex tasks may be linked to a neurological "reserve" that appears to compensate for behavioral performance (32). The concept of "reserve" is one that is more commonly used with respect to cognition $(34,35)$, posited to provide a protective effect against cognitive decline associated with aging or disease. One can think of enhanced skilled performance through years of training as offering this same level of protection against performance decline following brain injury, via more efficient and resilient brain networks needed in the control of complex skills.

\section{What About Low-Level Blast Exposure and Cognitive-Motor Integration Performance?}

In a recent study in collaboration with Development and Research Defense Canada, we examined the impact, literally, of repeated blast-wave exposure over a period of years. We did this by looking at the CMI performance of 19 breaching instructors (those who teach others how to forcefully open closed/locked entryways) and range staff having many years of service, which came with many years of exposure to low level blast explosions (Figure 1C). We compared their performance to that of 19 age- and sex-matched Canadian Armed Forces non-breacher control participants. Similar to what we observed in experienced athletes, our preliminary results show a significantly greater variability in reaction time $(p<$ 0.05 , equality of variance test) in the most challenging CMI condition in the breacher group (36). We also observed slower reaction times and worse accuracy in the standard (Cohen's D: 1.11, $p<0.01$ ) and horizontal (Cohen's D: 0.94, $p<$ 0.01 ) visuomotor conditions in the breacher group compared to controls (Figure 1D). The large variation in reaction time within the breacher group could be due to the differences in years of exposure to low levels of blast explosions during the breacher courses (37-40). Note that the source of performance decline may have come from subtle brain network alterations due to blast exposure (41), or could have arisen due to reduced function at the sensory input or neuromuscular output levels (or a combination of all these things). A comprehensive sensory, cognitive, and motor examination of this group (ongoing) will provide these important answers. However, it is also noteworthy that there were overall few CMI deficits in this group of breachers, similar to what we observed in the previously concussed elite-level athletes. Hence, these data suggest the presence of a motor skill reserve reflecting resilient neural movement control networks in these highly trained service members.

Overall, these studies highlight the importance of testing and assessing those affected by blast exposure and mild brain trauma with outcomes that require coordinated brain activity. Assessing motor or cognitive tasks alone do not demonstrate the ability to pick up on the interconnectivity impairments that appear to exist following concussive injuries. Put simply, we believe that multi-domain tasks reveal a failure to communicate, communication here referring to the interaction between different brain areas responsible for rule-based skilled performance.

\section{WHAT'S GOING ON IN THERE? THE NEURAL CORRELATES OF COGNITIVE-MOTOR INTEGRATION}

We know from behavioral studies that damage to the brain often results in deficits in CMI performance while leaving standard reaching intact. This observation suggests that the neural correlates of CMI differ from those used to produce standard reaching movements. To understand the additional neural control mechanisms involved in movement control using these different levels of gaze/reach dissociation, neuroimaging work in our laboratory has directly compared brain activity in tasks requiring CMI with standard visuomotor mapping. These data provide fundamental information about the neural control of complex movement, and provide insight into what is driving behavioral impairment following diffuse injury from mild head impact.

Many studies suggest that the brain couples eye and arm movements so that they are made to the same spatial location by default (42-44). Within the brain, neural signals associated with the control of the eyes and the arm converge in several regions. For example, posterior parietal cortex regions known to be essential for producing reaching movements encode reaches 
in an eye-centered frame of reference (45-47). Similarly, the production of arm moments influences activity within brain areas thought to be specific for eye position control $(48,49)$. The existence of neural circuitry that couples reach to gaze during standard tasks predicts the existence of regions that can inhibit this pairing (50). In a recent functional MRI study, we compared brain activity during standard reaching to activity associated with a CMI task in which saccades were made toward the cued location, but arm movements were made $180^{\circ}$ away from that location (51). This task required both decoupling reach from gaze, and incorporating an explicit rule to move the arm away from the cued target location. Patterns of activity within the cuneus region of the occipital cortex, an important sensorimotor hub (52-54), strongly distinguished between the two conditions, predicting whether the eyes and hand were going to move to the same or opposite target locations. Others have observed that damage to the cuneus is a common precursor to the development of optic ataxia (55-58), whereby patients show extremely poor accuracy when reaching for non-foveal targets (59-62). Together, these data suggest that the cuneus is likely crucial for decoupling reach from gaze during CMI tasks. We also observed that like the cuneus, spatial patterns of activity in the medial premotor cortex strongly distinguished between the CMI and standard tasks. Others have reported that when non-human primates learn two different CMI tasks, "context-dependent" cells in this region only fire for one of the two tasks (63). Further, when activity in this region of the brain is suppressed, deficits in switching between rules for different visuomotor associations occur (64). Taken together, these findings suggest that while the cuneus plays a role in allowing us to inhibit the default coupling of the eyes and arm, the medial premotor cortex is involved in incorporating explicit rules into motor plans that determine specifically how these effectors should be dissociated to satisfy the context of a given CMI task.

CMI tasks also require implicit sensorimotor recalibration. The relationships between visual information, patterns of muscle activity, and proprioceptive feedback are altered. We examined the effect of implicit recalibration in another fMRI study comparing standard hand movements to visual targets on a touch screen in the vertical plane to non-standard ones where the hand moved on a horizontally-placed touch screen (65). Both conditions generated almost completely overlapping activity in the typical motor, somatosensory, premotor, parietal, occipital, and cerebellar regions associated with visually guided reaching, and no differences in the amplitude of task-related activity. However, multi-voxel pattern analyses revealed that within these regions, patterns of activity strongly discriminated between the two tasks. As trials progressed from presentation of a cued target, to a delay period, to motor execution, task discrimination occurred in an increasing number of brain regions, eventually encompassing the majority of regions active in the two tasks (Figures 2A-C). In other words, although both conditions activated similar regions of the brain, the nature of this activity differed in ways that were strongly predictive of which visuomotor mapping was being performed. Taken as a whole, our imaging results in healthy adults demonstrate that each of the additional components required for CMI (i.e., inhibiting the default coupling of reach and gaze, incorporation of task-specific rules, and sensorimotor recalibration) exerts a distinct influence on how movements are accomplished by the brain.

\section{Sex- and Injury-Related Effects on the Control of Cognitive-Motor Integration}

We have observed that both CMI and standard visuomotor tasks evoke a notably more bilateral pattern of activity in premotor and parietal regions in women when compared to men. This phenomenon has been observed using both fMRI (66) and EEG (67). Such bilateral activity in reachrelated regions in women might provide protective functional redundancy capable of compensating for decreased activity in either hemisphere, as demonstrated by a study in which one such region (dorsal premotor cortex) was inhibited via transcranial magnetic stimulation (68). Importantly, these sexrelated differences are observed even when men and women demonstrate equal skill levels in the tasks (Figures 2D,E). Further, the nature of sex differences can depend upon the specific type of CMI task performed. For example, men had greater lateral sulcus activity than women for CMI tasks in which eye and hand movements were made in opposite directions but not when they moved in the same direction. Others have also observed a pattern of more bilateral brain activity in women relative to men when processing language $(69,70)$, emotion $(71-$ 73), and music (74). Therefore, the phenomenon of relatively bilateral patterns of activity in women is not limited to processes associated with motor control. Different sex-related patterns of brain activity imply that damage to the brain could result in different visuomotor-related deficits in men and women. These observations have important clinical implications and strongly indicate that neurological assessments and rehabilitation must ultimately be customized to best serve the needs of both male and female patients.

Preliminary imaging work has also begun to reveal how a history of concussion affects the neural correlates of CMI. Anatomical images were compared between women who were diagnosed with post-concussion syndrome (PCS) and women with no history of brain trauma (75). When comparing PCS participants to controls, we observed volume decreases in cerebellar regions that serve a variety of diverse roles including cognitive, sensorimotor, and vestibular functions (76). This wide-range of functions could be a factor in the observation that symptoms associated with PCS are quite variable (77). Diffusion-weighted images were also collected, and showed decreased fractional anisotropy (FA) that was associated with poorer CMI performance in several white matter tracts across all study participants (78). Taken with our previous observations that CMI relies upon numerous cortical regions throughout the brain, this finding emphasizes that healthy white matter connections within this network are also crucial for successful cognitive-motor integration. 

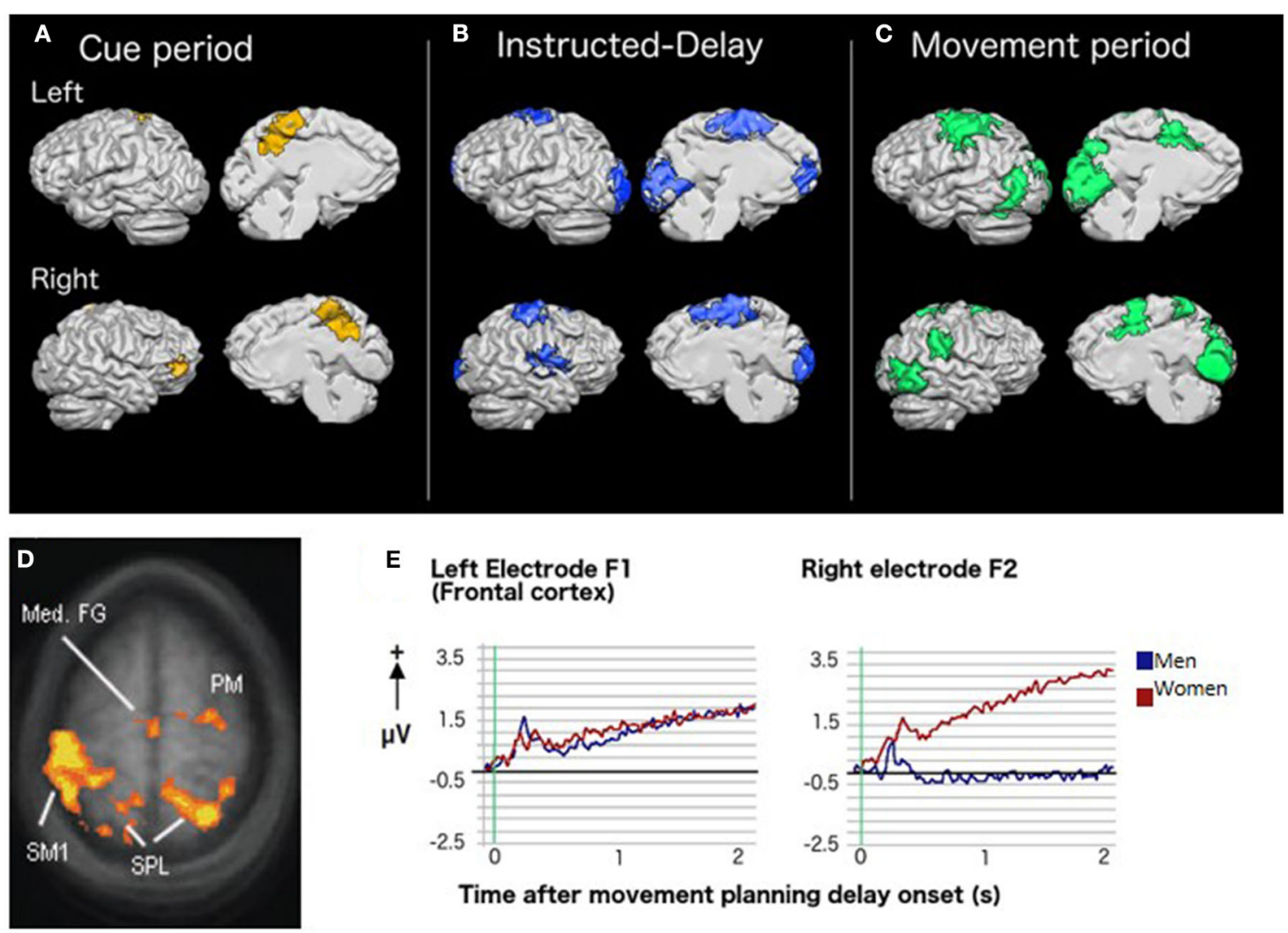

E Left Electrode F1 (Frontal cortex)
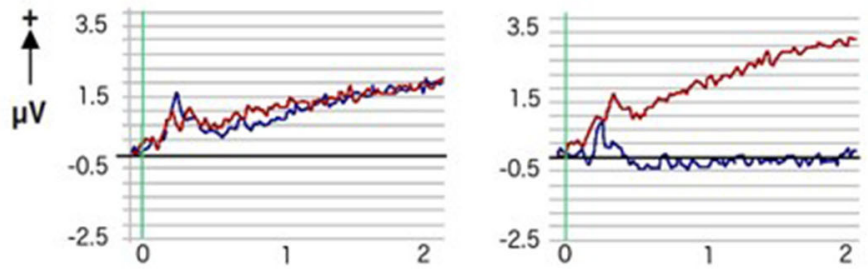

Time after movement planning delay onset (s)

FIGURE 2 | Brain activity and CMI: Results of group whole-brain recursive feature elimination multi-voxel pattern analysis. Colored regions represent voxels in which significant decoding of the standard vs. plane-change visuomotor mapping conditions occurred during (A) the cue period (yellow), (B) the instructed-delay period (blue), and (C) the movement period (green). Regions are shown overlaid on a Talairach-normalized brain from one participant. Within each panel, the left hemisphere is shown at the top and the right hemisphere is shown on the bottom. Lateral surfaces are shown on the left of each panel and medial surfaces on the right [adapted with permission from (65)]. (D) Sex-related differences in brain activity during rule-based skill performance. Frontal and parietal cortex regions with significantly higher fMRI BOLD signal in women relative to men during non-standard movement planning [adapted with permission from (66)]. (E) EEG slow cortical potentials over left and right frontal cortex during movement planning showing a more bilateral pattern of activity in women than men [adapted with permission from (67)].

\section{MOVING FORWARD, IN A THOUGHTFUL WAY}

As always with science, our research leaves us with more questions than answers. Moving forward, we believe it is important to quantify the effects of various factors that impact one's movement control response to blast exposure and blunt head trauma. Our findings around sex-related differences in the neural control of skill highlight the importance of examining factors such as hormonal influences on injury response, and sex-related vs. gender-related differences in brain network organization. The basic age-related differences we see in our younger vs. working-aged individuals in the studies reviewed here highlights the need to study the interactions between natural aging, skill reserve, and the long-term effects of mild brain injury through longitudinal research. What we are most enthusiastically pursuing at the moment, however, is research into counteracting the effects of compromised brain health through cognitivemotor interventions designed to strengthen the very neural control networks that appear to be affected by concussive injury and neuropathology $(79,80)$. Such a targeted approach holds promise as an effective means of stabilizing and improving one's functional abilities in the face of injury, allowing for a more enriched daily life.

\section{DATA AVAILABILITY STATEMENT}

The original contributions presented in the study are included in the article/supplementary material, further inquiries can be directed to the corresponding author/s.

\section{ETHICS STATEMENT}

The studies involving human participants were reviewed and approved by York University Human Participants Research Committee and the Human Research Ethics Committee of Defence Research and Development Canada. Written informed consent to participate in this study was provided by the participants' legal guardian/next of kin. 


\section{AUTHOR CONTRIBUTIONS}

LS conceptualized the review. LS, DG, MA, and DD conceptualized, wrote, and edited the manuscript. All authors contributed to the article and approved the submitted version.

\section{FUNDING}

The authors acknowledge the operating funding support from the Donald Sanderson Memorial Fund (LS), the

\section{REFERENCES}

1. Wise SP, Di Pellegrino G, Boussaoud D. The premotor cortex and nonstandard sensorimotor mapping. Can J Physiol Pharmacol. (1996) 74:46982. doi: 10.1139/y96-035

2. Bedford FL. Perceptual and cognitive spatial learning. J Exp Psychol Hum Percept Perform. (1993) 19:517. doi: 10.1037/0096-1523.19.3.517

3. Clower DM, Boussaoud D. Selective use of perceptual recalibration versus visuomotor skill acquisition. J Neurophysiol. (2000) 84:27038. doi: 10.1152/jn.2000.84.5.2703

4. Lackner JR, DiZio P. Motor control and learning in altered dynamic environments. Curr Opin Neurobiol. (2005) 15:6539. doi: 10.1016/j.conb.2005.10.012

5. Redding GM, Rossetti Y, Wallace B. Applications of prism adaptation: a tutorial in theory and method. Neurosci Biobehav Rev. (2005) 29:43144. doi: 10.1016/j.neubiorev.2004.12.004

6. Bock O. Basic principles of sensorimotor adaptation to different distortions with different effectors and movement types: a review and synthesis of behavioral findings. Front Hum Neurosci. (2013) 7:81. doi: 10.3389/fnhum.2013.00081

7. Denise Y, Henriques P, Erin K. Cressman. Visuomotor Adaptation and Proprioceptive Recalibration. J Motor Behav. (2012) 44:6:43544. doi: 10.1080/00222895.2012.659232

8. Bolouri H, Zetterberg H. Animal models for concussion: molecular and cognitive assessments-relevance to sport and military concussions. In: Kobeissy FH, ed. Brain Neurotrauma: Molecular, Neuropsychological, and Rehabilitation Aspects. Boca Raton, FL: CRC Press/Taylor \& Francis (2015) p. 1-21.

9. Choe MC. The pathophysiology of concussion. Curr Pain Headache Rep. (2016) 20:42. doi: 10.1007/s11916-016-0573-9

10. Giza CC, Hovda DA. The new neurometabloic cascade of concussion. Neurosurgery. (2015) 75:S24-S33. doi: 10.1227/NEU.0000000000000505

11. Barkhoudarian G, Hovda DA. The molecular pathophysiology of concussive brain injury. Clin J Sport Med. (2011) 30:3348. doi: 10.1016/j.csm.2010.09.001

12. Büki A, Povlishock JT. All roads lead to disconnection? Traumatic axonal injury revisited. Acta Neurochir (Wien). (2006) 148:181-94. doi: 10.1007/s00701-005-0674-4

13. Kaushal M, España LY, Nencka AS, Wang Y, Nelson LD, McCrea $\mathrm{MA}$, et al. Resting-state functional connectivity after concussion is associated with clinical recovery. Hum Brain Mapp. (2019) 40:121120. doi: 10.1002/hbm.24440

14. Hristopulos DT, Babul A, Babul S, Brucar LR, Virji-Babul N. Disrupted information flow in resting-state in adolescents with sports related concussion. Front Hum Neurosci. (2019) 13:419. doi: 10.3389/fnhum.2019.00419

15. Murdaugh DL, King TZ, Sun B, Jones RA, Ono KE, Reisner A, et al. Longitudinal changes in resting state connectivity and white matter integrity in adolescents with sports-related concussion. I Int Neuropsychol Soc. (2018) 24:890. J Int Neuropsychol Soc. (2018) 24:781-92. doi: 10.1017/S1355617718000413

16. Wright DK, Gardner AJ, Wojtowicz M, Iverson GL, O’Brien TJ, Shultz SR, et al. White matter abnormalities in retired professional
Natural Sciences and Engineering Research Council of Canada (LS), the Department of National Defence (DND) and the Canadian Forces Health Services, and the Canadian Institutes of Health Research (MOP125915, LS). Postdoctoral funding support provided by the VISTA Program, Canada First Research Excellence Fund (MA and DD). This research was undertaken as part of the Vision: Science to Applications program, thanks in part to funding from the Canada First Research Excellence Fund. rugby league players with a history of concussion. J Neurotrauma. (2020). doi: 10.1089/neu.2019.6886. [Epub ahead of print].

17. Churchill N, Hutchison MG, Leung G, Graham S, Schweizer TA. Changes in functional connectivity of the brain associated with a history of sport concussion: a preliminary investigation. Brain Injury. (2017) 31:3948. doi: 10.1080/02699052.2016.1221135

18. Shepherd HA, van Rassel C, Black A, Warryiar V, Graham R, Emery CA, et al. Feasibility and reliability of a novel game-based test of neurological function in youth: the equilibrium test battery. Clin J Sport Med. (2020) 30:e88-e110. doi: 10.1097/JSM.0000000000000844

19. Kis M. Reliability of a new test of balance function in healthy and concussion populations. J Funct Morphol Kinesiol. (2020) 5:13. doi: 10.3390/jfmk5010013

20. McGrath SP, McGrath ML, Bastola D. Developing a concussion assessment mHealth app for certified Athletic Trainers. AMIA Annu Symp Proc. (2018) 2017:1282-291.

21. Yang S, Flores B, Magal R, Harris K, Gross J, Ewbank A, et al. Diagnostic accuracy of tablet-based software for the detection of concussion. PLoS One. (2017) 12:e0179352. doi: 10.1371/journal.pone.0179352

22. Lee H, Sullivan SJ, Schneiders AG, Ahmed OH, Balasundaram AP, Williams D, et al. Smartphone and tablet apps for concussion road warriors (team clinicians): a systematic review for practical users. Br J Sports Med. (2015) 49:499-505. doi: 10.1136/bjsports-2013-092930

23. van Donkelaar P, Osternig L, Chou LS. Attentional and biomechanical deficits interact after mild traumatic brain injury. Exer Sport Sci Rev. (2006) 34:7782. doi: 10.1249/00003677-200604000-00007

24. Ventura RE, Balcer LJ, Galetta SL, Rucker JC. Ocular motor assessment in concussion: current status and future directions. J Neurol Sci. (2016) 361:79-86. doi: 10.1016/j.jns.2015.12.010

25. Alsalaheen BA, Whitney SL, Marchetti GF, Furman JM, Kontos AP, Collins $\mathrm{W}$, et al. Relationship between cognitive assessment and balance measures in adolescents referred for vestibular physical therapy after concussion. Clin J Sport Med. (2016) 26:46. doi: 10.1097/JSM.0000000000000185

26. Broglio SP, Macciocchi SN, Ferrara MS. Sensitivity of the concussion assessment battery. Neurosurgery. (2007) 60:10508. doi: 10.1227/01.NEU.0000255479.90999.C0

27. Cassidy JD, Carroll L, Peloso P, Borg J, Von Holst H, Holm L, et al. Incidence, risk factors and prevention of mild traumatic brain injury: results of the WHO Collaborating Center Task Force on Mild Traumatic Brain Injury. J Rehab Med. (2004) 36:28-60. doi: 10.1080/165019604100 23732

28. Delaney JS, Lamfookon C, Bloom GA, Al-Kashmiri A, Correa JA. Why university athletes choose not to reveal their concussion symptoms during a practice or game. Clin J Sport Med. (2015) 25:113-25. doi: 10.1097/JSM.0000000000000112

29. Brown JA, Dalecki M, Hughes C, Macpherson AK, Sergio LE. Cognitivemotor integration deficits in young adult athletes following concussion. BMC Sports Sci Med Rehab. (2015) 7:25. doi: 10.1186/s13102-015-0019-4

30. Dalecki M, Albines D, Macpherson A, Sergio LE. Prolonged cognitivemotor impairments in children and adolescents with a history of concussion. Concussion. (2016) 1:CNC14. doi: 10.2217/cnc-2016-0001

31. Dalecki M, Gorbet DJ, Macpherson A, Sergio LE. Sport experience is correlated with complex motor skill recovery in youth following concussion. Eur J Sport Sci. (2019) 19:1257-66. doi: 10.1080/17461391.2019.1584249 
32. Hurtubise J, Gorbet D, Hamandi Y, Macpherson A, Sergio L. The effect of concussion history on cognitive-motor integration in elite hockey players. Concussion. (2016) 1:CNC17. doi: 10.2217/cnc-2016-0006

33. McCrory P, Meeuwisse W, Dvorak J, Aubry M, Bailes J, Broglio S, et al. Consensus statement on concussion in sport-the 5 th international conference on concussion in sport held in Berlin, October 2016. Br J Sports Med. (2017) 51:838-47. doi: 10.1136/bjsports-2017-097699

34. Craik FI, Bialystok E, Freedman M. Delaying the onset of Alzheimer disease: bilingualism as a form of cognitive reserve. Neurology. (2010) 75:17269. doi: 10.1212/WNL.0b013e3181fc2a1c

35. Soldan A, Pettigrew C, Albert M. Cognitive reserve from the perspective of preclinical alzheimer disease: a review. Clin Geriatr Med. (2020) 36:247-63. doi: 10.1016/j.cger.2019.11.006

36. Tenn C, Vartanian O, Sergio L, Gorbet D, Nakashima A, Rhind, et al. The impact of repetitive low-level blast exposures on cognitive-motor integration in Canadian Armed Forces Breachers. In: Soc. For Neuroscience Annual Meeting 250.12, San Diego, CA (2000).

37. Goldstein K. After Effects of Brain Injury in War. New York, NY: Grune and Stratton (1942).

38. Carr W, Polejaeva E, Grome A, Crandall B, LaValle C, Eonta $\mathrm{SE}$, et al. Relation of repeated low-level blast exposure with symptomology similar to concussion. J Head Trauma Rehab. (2015) 30:47-55. doi: 10.1097/HTR.0000000000000064

39. Carr W, Stone JR, Walilko T, Young LA, Snook TL, Paggi ME, et al. Repeated low-level blast exposure: a descriptive human subjects study. Military Med. (2016) 181:28-39. doi: 10.7205/MILMED-D-15-00137

40. Elder GA, Stone JR, Ahlers ST. Effects of low-level blast exposure on the nervous system: is there really a controversy? Front Neurol. (2014) 5:269. doi: 10.3389/fneur.2014.00269

41. Thies SB, Tresadern PA, Kenney LP, Smith J, Howard D, Goulermas JY, et al. Movement variability in stroke patients and controls performing two upper limb functional tasks: a new assessment methodology. J Neuroeng Rehab. (2009) 6:2. doi: 10.1186/1743-0003-6-2

42. Gielen CC, van den Heuvel PJ, van Gisbergen JA. Coordination of fast eye and arm movements in a tracking task. Exp brain Res. (1984) 56:15461. doi: 10.1007/BF00237452

43. Herman R, Herman R, Maulucci R. Visually triggered eye-arm movements in man. Exp Brain Res. (1981) 42:392-8. doi: 10.1007/BF00237504

44. Prablanc C, Echallier JF, Komilis E, Jeannerod M. Optimal response of eye and hand motor systems in pointing at a visual target. I. Spatio-temporal characteristics of eye and hand movements and their relationships when varying the amount of visual information. Biol Cybern. (1979) 35:11324. doi: $10.1007 / \mathrm{BF} 00337436$

45. Batista AP, Buneo CA, Snyder LH, Andersen RA. Reach plans in eye-centered coordinates. Science. (1999) 285:257-60. doi: 10.1126/science.285.5425.257

46. Crawford JD, Medendorp WP, Marotta JJ. Spatial transformations for eye-hand coordination. J Neurophysiol. (2004) 92:109. doi: 10.1152/jn.00117.2004

47. Cohen YE, Andersen RA. A common reference frame for movement plans in the posterior parietal cortex. Nat Rev. (2002) 3:553-62. doi: 10.1038/ nrn873

48. Mushiake H, Fujii N, Tanji J. Visually guided saccade versus eye-hand reach: contrasting neuronal activity in the cortical supplementary and frontal eye fields. J Neurophysiol. (1996) 75:2187-91. doi: 10.1152/jn.1996.75.5.2187

49. Reyes-Puerta V, Philipp R, Lindner W, Hoffmann K-P. Role of the rostral superior colliculus in gaze anchoring during reach movements. $J$ Neurophysiol. (2010) 103:3153-66. doi: 10.1152/jn.00989.2009

50. Gorbet DJ, Staines WR, Sergio LE. Brain mechanisms for preparing increasingly complex sensory to motor transformations. Neuroimage. (2004) 23:1100-11. doi: 10.1016/j.neuroimage.2004.07.043

51. Gorbet DJ, Sergio LE. Don't watch where you're going: the neural correlates of decoupling eye and arm movements. Behav Brain Res. (2016) 298:22940. doi: 10.1016/j.bbr.2015.11.012

52. Kravitz DJ, Saleem KS, Baker CI, Mishkin M. A new neural framework for visuospatial processing. Nat Rev Neurosci. (2011) 12:217-30. doi: 10.1167/11.11.923

53. Passarelli L, Rosa MGP, Gamberini M, Bakola S, Burman KJ, Fattori P, et al. Cortical connections of area V6Av in the macaque: a visual-input node to the eye/hand coordination system. J Neurosci. (2011) 31:1790801. doi: 10.1523/JNEUROSCI.4784-10.2011

54. Galletti C, Kutz DF, Gamberini M, Breveglieri R, Fattori P. Role of the medial parieto-occipital cortex in the control of reaching and grasping movements. Exp brain Res. (2003) 153:158-70. doi: 10.1007/s00221-003-1589-Z

55. Jakobson LS, Archibald YM, Carey DP, Goodale MA. A kinematic analysis of reaching and grasping movements in a patient recovering from optic ataxia. Neuropsychologia. (1991) 29:803-9. doi: 10.1016/0028-3932(91) 90073-H

56. Pellijeff A, Bonilha L, Morgan PS, McKenzie K, Jackson SR. Parietal updating of limb posture: an event-related fMRI study. Neuropsychologia. (2006) 44:2685-90. doi: 10.1016/j.neuropsychologia.2006.01.009

57. Karnath HO, Perenin MT. Cortical control of visually guided reaching: evidence from patients with optic ataxia. Cereb Cortex. (2005) 15:15619. doi: 10.1093/cercor/bhi034

58. Granek J, Pisella L, Stemberger J, Vighetto A, Rossetti Y, Sergio LE. Decoupled visually-guided reaching in optic ataxia: differences in motor control between canonical and non-canonical orientations in space. PLoS One. (2013) 8:e0086138. doi: 10.1371/journal.pone.0086138

59. Granek JA, Pisella L, Blangero A, Rossetti Y, Sergio LE. The role of the caudal superior parietal lobule in updating hand location in peripheral vision: further evidence from optic ataxia. PLoS One. (2012) 7:e46619. doi: 10.1371/journal.pone.0046619

60. Buxbaum LJ, Coslett HB. Subtypes of optic ataxia: reframing the disconnection account. Neurocase. (1997) 3:15966. doi: 10.1093/neucas/3.3.159

61. Battaglia-Mayer A, Caminiti R. Optic ataxia as a result of the breakdown of the global tuning fields of parietal neurones. Brain. (2002) 125:22537. doi: 10.1093/brain/awf034

62. Jackson SR, Newport R, Husain M, Fowlie JE, O'Donoghue $\mathrm{M}$, Bajaj N. There may be more to reaching than meets the eye: re-thinking optic ataxia. Neuropsychologia. (2009) 47:1397408. doi: 10.1016/j.neuropsychologia.2009.01.035

63. Crutcher MD, Russo GS, Ye S, Backus DA. Target-, limb-, and context-dependent neural activity in the cingulate and supplementary motor areas of the monkey. Exp Brain Res. (2004) 158:278-88. doi: 10.1007/s00221-004-1895-0

64. Rushworth MFS, Hadland KA, Paus T, Sipila PK. Role of the human medial frontal cortex in task switching: a combined fMRI and TMS study. $J$ Neurophysiol. (2002) 87:2577-92. doi: 10.1152/jn.2002.87.5.2577

65. Gorbet DJ, Sergio LE. Looking up while reaching out: the neural correlates of making eye and arm movements in different spatial planes. Exp Brain Res. (2019) 237:57-70. doi: 10.1007/s00221-018-5395-Z

66. Gorbet DJ, Sergio LE. Preliminary sex differences in human cortical BOLD fMRI activity during the preparation of increasingly complex visually guided movements. Eur J Neurosci. (2007) 25:1228-39. doi: 10.1111/j.1460-9568.2007.05358.x

67. Gorbet DJ, Mader LB, Richard Staines W. Sex-related differences in the hemispheric laterality of slow cortical potentials during the preparation of visually guided movements. Exp Brain Res. (2010) 202:633-46. doi: 10.1007/s00221-010-2170-1

68. Gorbet DJ, Staines WR. Inhibition of contralateral premotor cortex delays visually guided reaching movements in men but not in women. Exp Brain Res. (2011) 212:315-25 doi: 10.1007/s00221-011-2731-y

69. Shaywitz BA, Shaywltz SE, Pugh KR, Constable RT, Skudlarski P, Fulbright RK, et al. Sex differences in the functional organization of the brain for language. Nature. (1995) 373:607-9. doi: 10.1038/373607a0

70. Clements A M, Rimrodt SL, Abel JR, Blankner JG, Mostofsky SH, Pekar JJ et al. Sex differences in cerebral laterality of language and visuospatial processing. Brain Lang. (2006) 98:150-8. doi: 10.1016/j.bandl.2006. 04.007

71. Wager TD, Phan KL, Liberzon I, Taylor SF. Valence, gender, and lateralization of functional brain anatomy in emotion: a meta-analysis of findings from neuroimaging. Neuroimage. (2003) 19:513-31. doi: 10.1016/S1053-8119(03)00078-8

72. Hall GB, Witelson SF, Szechtman H, Nahmias C. Sex differences in functional activation patterns revealed by increased emotion processing demands. Neuroreport. (2004) 15:219-23. doi: 10.1097/00001756-200402090-00001 
73. Williams LM, Barton MJ, Kemp AH, Liddell BJ, Peduto A, Gordon E, et al. Distinct amygdala-autonomic arousal profiles in response to fear signals in healthy males and females. Neuroimage. (2005) 28:61826. doi: 10.1016/j.neuroimage.2005.06.035

74. Flores-Gutiérrez EO, Díaz JL, Barrios FA, Guevara MÁ, del RíoPortilla Y, Corsi-Cabrera M. Differential alpha coherence hemispheric patterns in men and women during pleasant and unpleasant musical emotions. Int J Psychophysiol. (2009) 71:43-9. doi: 10.1016/j.ijpsycho.2008. 07.007

75. Hurtubise J, Gorbet DJ, Sergio LE. Cognitive-motor integration performance, symptoms, and cerebellum volume in females with post-concussion syndrome. In: Soc. For Neuroscience Annual Meeting. Chicago, IL (2015).

76. Stoodley CJ, Schmahmann JD. Functional topography of the human cerebellum. Handb Clin Neurol. (2018) 154:5970. doi: 10.1016/B978-0-444-63956-1.00004-7

77. Polinder S, Cnossen MC, Real RGL, Covic A, Gorbunova A, Voormolen DC, et al. A multidimensional approach to post-concussion symptoms in mild traumatic brain injury. Front Neurol. (2018) 9:1113. doi: 10.3389/fneur.2018.01113

78. Hurtubise J, Gorbet DJ, Hynes LM, Macpherson A, Sergio L. White matter integrity and its relationship to cognitive-motor integration in females with and without post-concussion syndrome. J Neurotrauma. (2020) 37:152836. doi: 10.1089/neu.2019.6765

79. de Boer C, Echlin HV, Rogojin A, Baltaretu BR, Sergio LE. Thinking-whilemoving exercises may improve cognition in elderly with mild cognitive deficits: a proof-of-principle study. Dement Geriatr Cogn Disord Extra. (2018) 8:248-58. doi: 10.1159/000490173

80. Echlin HE, Gorbet DJ, Sergio LE. Assessment of a cognitive-motor training program in adults at-risk for developing dementia. Can Geriatr J. (2020) 23:190-8. doi: 10.5770/cgj.23.394

Conflict of Interest: The authors declare that the research was conducted in the absence of any commercial or financial relationships that could be construed as a potential conflict of interest.

Copyright (C) 2020 Sergio, Gorbet, Adams and Dobney. This is an open-access article distributed under the terms of the Creative Commons Attribution License (CC BY). The use, distribution or reproduction in other forums is permitted, provided the original author(s) and the copyright owner(s) are credited and that the original publication in this journal is cited, in accordance with accepted academic practice. No use, distribution or reproduction is permitted which does not comply with these terms. 